\title{
Updating source term and atmospheric dispersion simulations for the dose reconstruction in Fukushima Daiichi Nuclear Power Station Accident
}

\author{
Haruyasu Nagai $^{1,{ }^{*}}$, Hiroaki Terada ${ }^{1}$, Katsunori Tsuduki ${ }^{1}$, Genki Katata ${ }^{1}$, Masakazu Ota $^{1}$, Akiko Furuno $^{1}$, and Shusaku \\ $\mathrm{Akari}^{2}$ \\ ${ }^{1}$ Nuclear Science and Engineering Center, Japan Atomic Energy Agency, 2-4 Shirakata, Tokai, Ibaraki, 319-1195 Japan \\ ${ }^{2}$ Makuhari System Laboratory, Fujitsu Limited, 1-9-3 Nakase, Mihama-ku, Chiba, 261-8588 Japan
}

\begin{abstract}
In order to assess the radiological dose to the public resulting from the Fukushima Daiichi Nuclear Power Station (FDNPS) accident in Japan, especially for the early phase of the accident when no measured data are available for that purpose, the spatial and temporal distribution of radioactive materials in the environment are reconstructed by computer simulations. In this study, by refining the source term of radioactive materials discharged into the atmosphere and modifying the atmospheric transport, dispersion and deposition model (ATDM), the atmospheric dispersion simulation of radioactive materials is improved. Then, a database of spatiotemporal distribution of radioactive materials in the air and on the ground surface is developed from the output of the simulation. This database is used in other studies for the dose assessment by coupling with the behavioral pattern of evacuees from the FDNPS accident. By the improvement of the ATDM simulation to use a new meteorological model and sophisticated deposition scheme, the ATDM simulations reproduced well the ${ }^{137} \mathrm{Cs}$ and ${ }^{131} \mathrm{I}$ deposition patterns. For the better reproducibility of dispersion processes, further refinement of the source term was carried out by optimizing it to the improved ATDM simulation by using new monitoring data.
\end{abstract}

\section{Introduction}

The Fukushima Daiichi Nuclear Power Station (FDNPS) accident in Japan, which was triggered by the magnitude 9.0 earthquake and resulting tsunami on March 11, 2011, caused a month-long discharge of significant amount of radioactive materials into the atmosphere. In order to assess the radiological dose to the public resulting from this release, there are some issues to be solved. One is for the internal dose due to short lived radionuclides such as radioiodine during the early phase of the accident, which cannot be assessed by using measured data. Another is for the external dose due to the direct radiation from radioactive plume and the ground shine at the point without measurement, which were considered to have large temporal variation caused by several plume passages. To solve these problems, the atmospheric transport, dispersion and deposition model (ATDM) simulation that can reproduce the spatial and temporal distribution of radioactive materials is useful. By simulating atmospheric dispersion conditions to be consistent with measurements, calculation results can complement spatiotemporally discrete measurements for dose assessment.

The source term of radioactive materials released into the atmosphere during the FDNPS accident is essential to evaluate the environmental distribution of radioactive materials. We have estimated the source term by comparing measurements of air concentration of radioactive materials or dose rate in the environment with calculated results by ATDM [1-4]. The ATDM used in these studies is WSPEEDI (Worldwide version of System for Prediction of Environmental Emergency Dose Information) [5] developed by the Japan Atomic Energy Agency (JAEA). Our source term has been validated by comparing with other estimations or by using in simulations of ATDMs [4, 6, 7]. The United Nations Scientific Committee on the Effects of Atomic Radiation (UNSCEAR) has used our source term [4] for estimating levels of radioactive material in the terrestrial environment and doses to the public, because they were derived from, and the models were already optimized to fit measurements of radioactive material in the environment [8]. However, UNSCEAR also pointed out in its 2013 report that the source term has large uncertainties and needs to be improved in future studies, in particular as more information becomes available on the progression of the accident, greater use is made of measurements in the environment, and improved assessment methods are implemented [8].

To improve our source term, we recently made detailed source term estimation by using additional monitoring data near the FDNPS and WSPEEDI including new deposition scheme [9]. The simulation of modified WSPEEDI and the new source term

\footnotetext{
* Corresponding author: nagai.haruyasu@jaea.go.jp
} 
successfully reproduced the local and regional deposition pattern of ${ }^{131} \mathrm{I}$ and ${ }^{137} \mathrm{Cs}$ derived from airborne monitoring by the United States Department of Energy (US-DOE) and Ministry of Education, Culture, Sports, Science and Technology (MEXT) [10, 11].

In this study, new source term and updated WSPEEDI simulations are used to reconstruct the spatial and temporal distribution of radioactive materials in the environment during the FDNPS accident. Then, a database of spatiotemporal distribution of radioactive materials in the air and on the ground surface is developed from the output of the WSPEEDI simulations. For the better reproducibility of dispersion processes provided by the database, further refinement of the source term is also carried out by optimizing it to the improved ATDM simulation. This database is used for the comprehensive dose assessment by coupling with the behavioral pattern of evacuees from the FDNPS accident. It can also provide basic information and simulation techniques to understand environmental impacts by the accident and to predict future conditions.

\section{Materials and method}

\subsection{New source term}

The source term, which is necessary for ATDM simulations to set up release condition of radioactive materials, was refined by considering the particle size and chemical form of radionuclides, and giving temporal change with short time step. For this purpose, the source term estimated by Katata et al. [9] was the most appropriate one in the published source terms, and was used in this study. The temporal change in release rate of ${ }^{131}$ I from 12 to 24 March 2011 estimated by Katata et al. [9] is shown in Fig. 1. This source term (new source term) is the latest update after the series of source term estimations by the combined analysis of environmental monitoring data and ATDM simulations at JAEA [1-4]. The major improvements from the source term used by UNSCEAR [4] are as follows:

- Air dose rates from automatic monitoring posts of Fukushima Prefecture [12], which are located within $20 \mathrm{~km}$ from FDNPS, during the period from March 12 $-16,2011$ were used.

- Deposition distributions of ${ }^{131} \mathrm{I}$ and ${ }^{137} \mathrm{Cs}$ on April 3, 2011 derived from the US-DOE and MEXT airborne survey [11] were used.

- The estimation method with coupled simulations of atmospheric and oceanic dispersion models using concentrations of ${ }^{134} \mathrm{Cs}$ and ${ }^{137} \mathrm{Cs}$ in marine surface over the Pacific Ocean observed during the period from April 2 to May 17, 2011 [13] was applied to correct the release rate during the period when the plume flowed toward the Pacific Ocean.

- The atmospheric dispersion model was modified to include sophisticated deposition scheme [9].

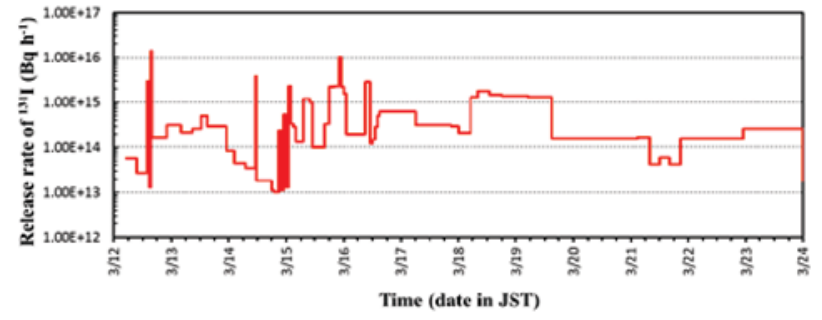

Fig. 1. Temporal change in estimated release rate of ${ }^{131} \mathrm{I}$.

\subsection{Improvement of ATDM simulation}

The ATDM used in this study is WSPEEDI [5] developed by JAEA. The original WSPEEDI consists of non-hydrostatic mesoscale atmospheric model MM5 [14] and Lagrangian particle dispersion model GEARN [5]. MM5 is a community model having many users all over the world. The Lagrangian particle dispersion model GEARN calculates the atmospheric dispersion of radionuclides by tracing the trajectories of a large number (typically a million) of marker particles discharged from a release point. By using meteorological field predicted by MM5, it calculates the movement of each particle affected by both the advection due to mean wind and subgrid scale turbulent eddy diffusion. A part of the radioactivity in the air is deposited on the ground surface by turbulence (dry deposition) and precipitation (wet deposition).

Both meteorological and dispersion models have been changed in this study. For the meteorological model, a new meteorological model (WRF) [15] and data assimilation method (WRF-DA) [16] are introduced. WRF is the updated model of MM5, and has many new physical options and functions including advanced data assimilation method WRF-DA. GEARN have been modified to use a sophisticated deposition scheme. The new scheme deals with dry and fog-water deposition, cloud condensation nuclei (CCN) activation, and subsequent wet scavenging due to mixed-phase cloud microphysics (in-cloud and below-cloud scavenging) for radioactive iodine gas $\left(\mathrm{I}_{2}\right.$ and $\left.\mathrm{CH}_{3} \mathrm{I}\right)$ and other particles (CsI, Cs, and Te) as shown in Fig. 2 [9].

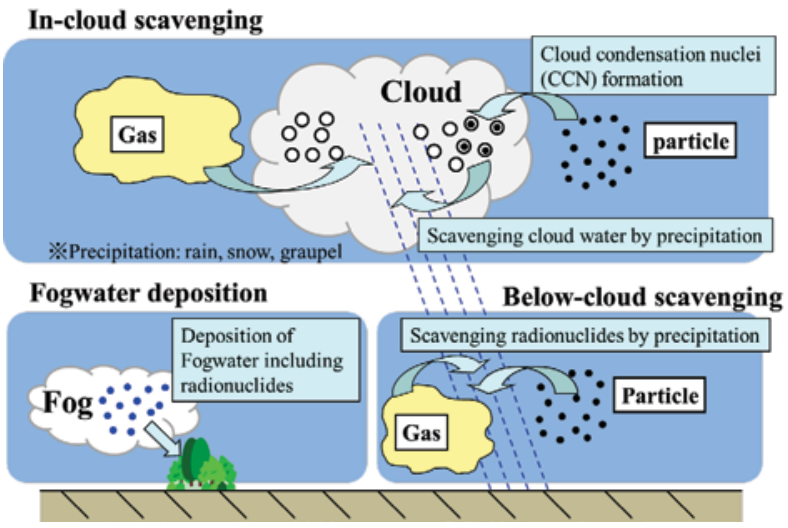

Fig. 2. Processes considered in the new wet deposition scheme. 
ATDM simulations by the new model using the new source term were carried out. Simulation results by various calculation conditions including results by the old model and source term used in UNSCEAR 13 report (UNSCEAR source term) were compared with measured surface deposition, and the reproducibility of new model is evaluated.

\subsection{Development of database}

A database of spatiotemporal distribution of radioactive materials in the air and on the ground surface has been constructed by developing calculation and analysis methods for database as shown in Fig. 3. At first, meteorological calculations are carried out by using MM5, WRF, and WRF-DA to make dataset of meteorological fields. Then, the dispersion calculation by using the modified dispersion model (GEARN-new) is conducted with unit release condition for a time segment (one hour) of release period. This calculation is carried out for each combination of meteorological field, nuclide type considering deposition property, release height, and release time segment, and matrix outputs for every calculation conditions are made.

The spatiotemporal distribution of air concentration and surface deposition of radioactive materials for any condition of source term can be reproduced immediately by linear combination of matrix outputs. Therefore, it is easy to compare results applying many kinds of source term with monitoring data, and find out the optimum source term with which the difference between calculations and measurements can be minimized. The optimum source term and resulting spatiotemporal distribution of radioactive materials in the environment are used for the assessment of radiological dose to the public.

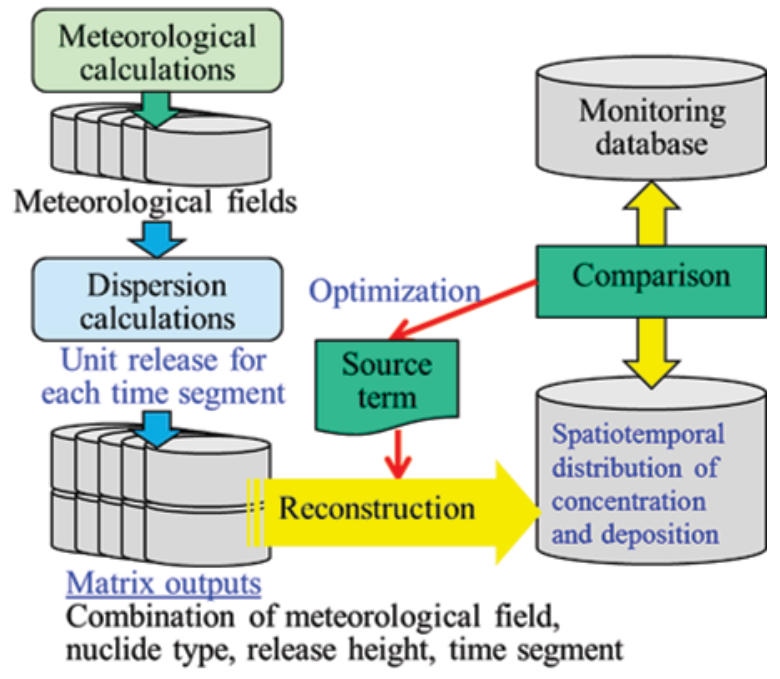

Fig. 3. Calculation and analysis methods for database.

\subsection{Optimization of the source term using the database and new monitoring data}

In the database, dataset by ATDM simulations with combinations of the meteorological model (MM5, WRF, and WRF-DA) and modified dispersion model (new GEARN) are stored. The spatiotemporal distribution of air concentration and surface deposition of radioactive materials can be reproduced by applying the source term to the dataset of each ATDM simulation. In this study, the new source term [9] was used as the most appropriate one in the published source terms. Since this source term was estimated by using the meteorological model MM5 and dispersion model (new GEARN) [9], it is considered to provide the optimum result by applying to the dataset of ATDM simulation with MM5 and new GEARN. Although the new meteorological model WRF and data assimilation method WRF-DA can possibly provide better meteorological fields, the difference of meteorological field from one by MM5 can cause the increase of discrepancy between the measurements and dispersion calculation results using the new source term. In addition to this, new monitoring data that have hourly atmospheric ${ }^{134} \mathrm{Cs}$ and ${ }^{137} \mathrm{Cs}$ radioactivity concentrations derived by analysing suspended particulate matter (SPM) collected at air pollution monitoring station [17] have been available after the estimation of the new source term. Therefore, optimization of the source term for ATDM simulations with new meteorological field is necessary.

The optimization of the source term was carried out by comparing hourly air concentration of ${ }^{137} \mathrm{Cs}$ between simulations and new measurements derived from SPM samples [17]. SPM samples at 99 sampling points have been analysed and published as the dataset. In this dataset 71 points using glass fiber sampling tape, which is less likely to have cross-contamination due to the apposition than polytetrafluoroethylene (PTFE) sampling tape, and one point near the FDNPS using PTFE sampling tape were used for the comparison. These 72 sampling points used for the comparison are shown in Fig. 4.

(a)

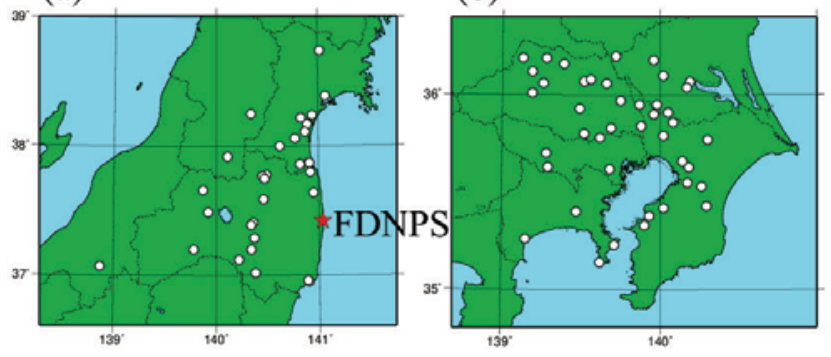

Fig. 4. Sampling points in (a) Fukushima, Miyagi, Yamagata, and Niigata Prefectures, and (b) Kanto region used for the comparison between simulated and measured air concentrations of ${ }^{137} \mathrm{Cs}$.

\section{Results and discussion}

\subsection{Performance test of ATDM}

Simulated deposition patterns of ${ }^{137} \mathrm{Cs}$ by combination of models (MM5 or WRF, old GEARN or new GEARN) 
and source terms (UNSCEAR source term [4] or new source term [9]) are shown in Fig. 5. Also, deposition patterns of ${ }^{137} \mathrm{Cs}$ by the airborne monitoring by MEXT [10] and simulation with the combination of WRF-DA, new GEARN, and new source term are shown in Fig. 6.
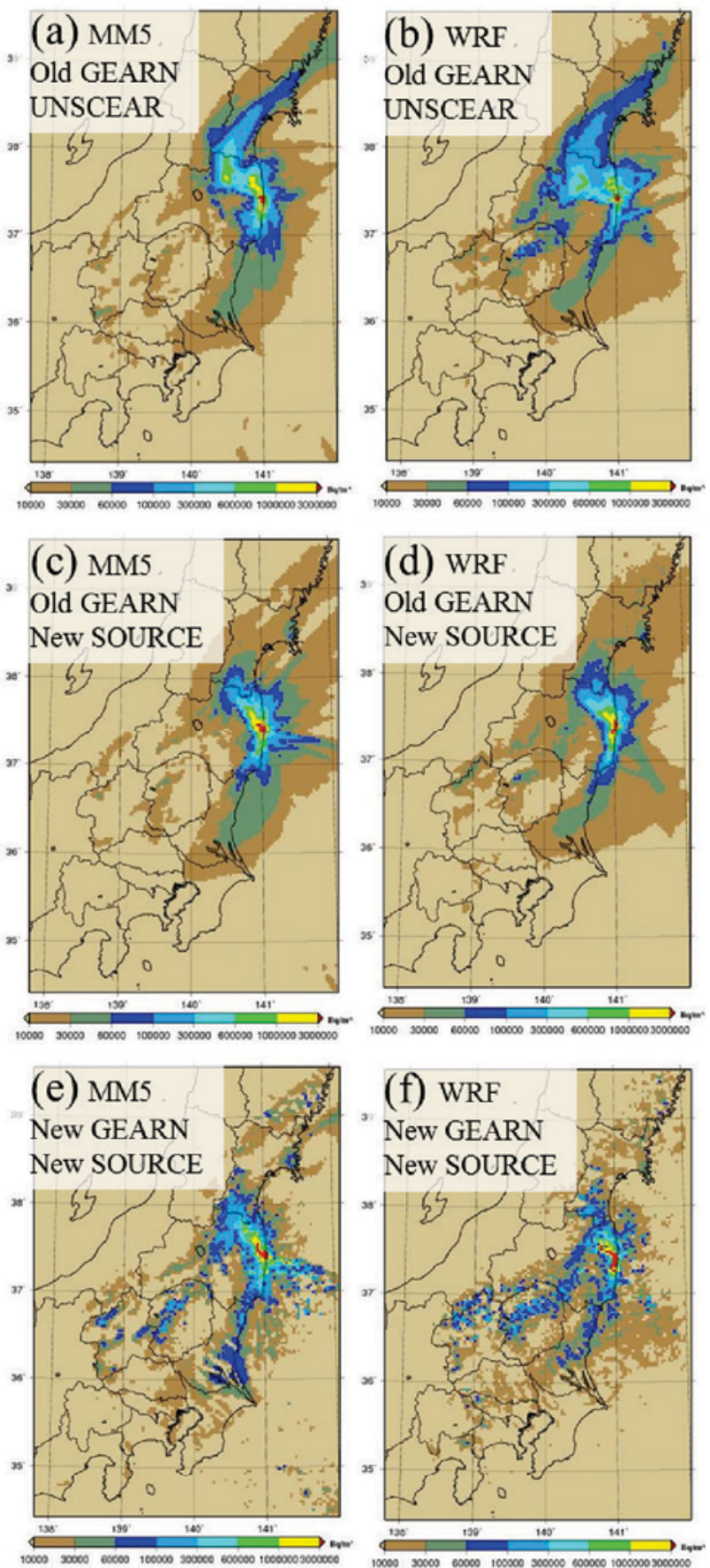

Fig. 5. Deposition patterns of ${ }^{137} \mathrm{Cs}$ by simulations with combination of (a) MM5, old GEARN, and UNSCEAR source term, (b) WRF, old GEARN, and UNSCEAR source term, (c) MM5, old GEARN, and new source term, (d) WRF, old GEARN, and new source term, (e) MM5, new GEARN, and new source term, and (f) WRF, new GEARN, and new source term.

In the cases using the former meteorological model MM5 (Fig. 5(a), (c), (e)), the reproducibility of ${ }^{137} \mathrm{Cs}$ deposition pattern was increased by using the new source term and new GEARN, especially around southwestern and northern areas from FDNPS, where the original WSPEEDI (Fig. 5(a)) under- and over-estimated, respectively, compared with the ${ }^{137} \mathrm{Cs}$ deposition of airborne monitoring (Fig. 6(a)).
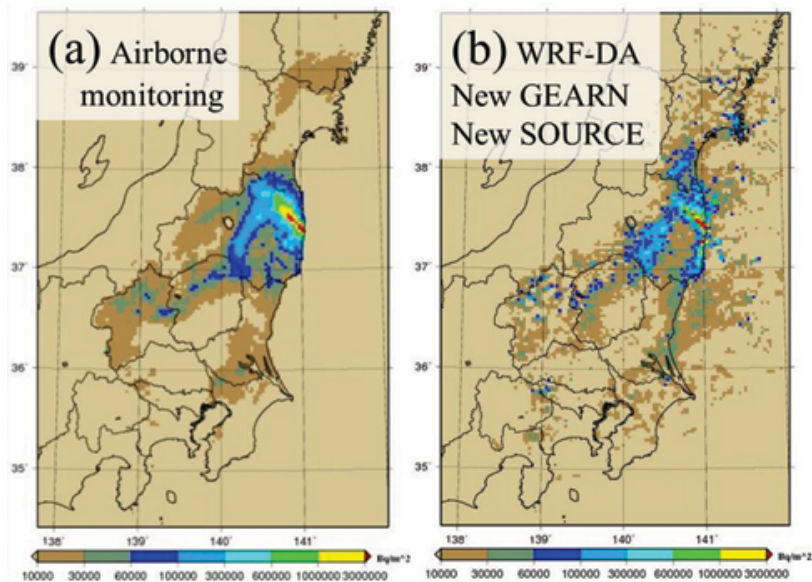

Fig. 6. Deposition patterns of ${ }^{137} \mathrm{Cs}$ of (a) the airborne monitoring by MEXT, and (b) simulation with combination of WRF-DA, new GEARN, and new source term. (a) Measured ${ }^{137} \mathrm{Cs}$

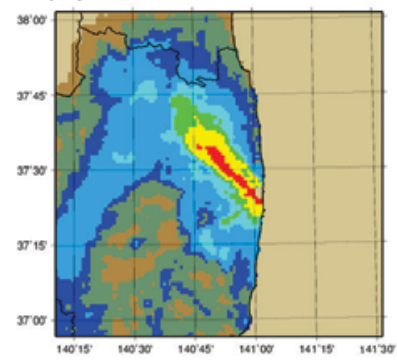

(c) Calculated ${ }^{137} \mathrm{Cs}$

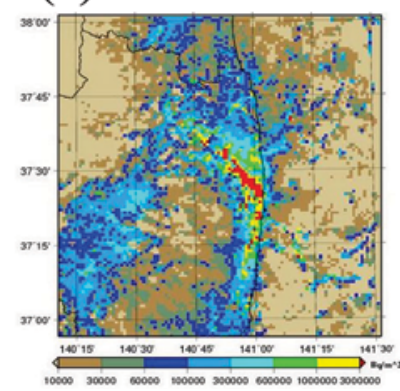

(b) Measured ${ }^{131} \mathrm{I}$

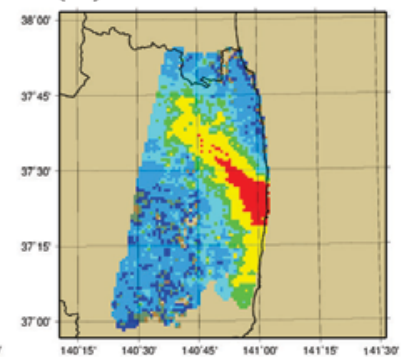

(d) Calculated ${ }^{131} \mathrm{I}$

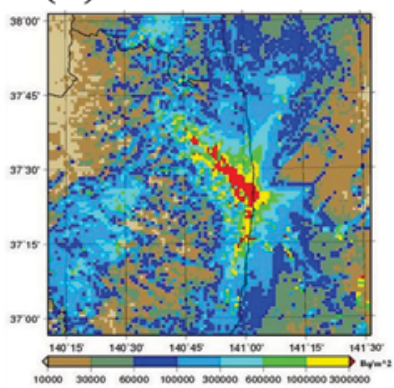

Fig. 7. Local deposition patterns of (a) ${ }^{137} \mathrm{Cs}$ and (b) ${ }^{131} \mathrm{I}$ by the airborne monitoring by MEXT, and (c) ${ }^{137} \mathrm{Cs}$ and (d) ${ }^{131} \mathrm{I}$ by simulation with combination of WRF-DA, new GEARN, and new source term.

The utilization of new meteorological model WRF had both positive and negative effects on the reproducibility of ${ }^{137} \mathrm{Cs}$ deposition pattern (Fig. 5(b), (d), (f)). For the deposition pattern of the eastern Japan scale, simulations using WRF agreed better with measurement than those using MM5. This indicates that WRF has 
higher performance in meteorological field prediction than MM5. However, the reproducibility of ${ }^{137} \mathrm{Cs}$ deposition pattern in the vicinity of FDNPS was decreased by using WRF. It is considered that the source term was optimized to the ATDM simulation with MM5 and a small difference in meteorological field between MM5 and WRF may cause a large difference in timing of plume passage and, consequently, deposition pattern.

By using the meteorological field by WRF-DA, the reproducibility of ${ }^{137} \mathrm{Cs}$ deposition pattern became higher than that by WRF (Fig. 6(b)). It is considered that WRFDA successfully simulated actual meteorological field more appropriately than MM5 and WRF by assimilating observed meteorological data. Although MM5 simulation also used the data assimilation, the data assimilation method of WRF-DA is more advanced and can provide better meteorological field. The good performance of ATDM simulation with WRF-DA is also shown in the comparison of local deposition patterns of ${ }^{137} \mathrm{Cs}$ and ${ }^{131} \mathrm{I}$ (Fig. 7). Therefore, it is considered that ATDM simulation with WRF-DA and new GEARN can provide better results of spatiotemporal distribution of air concentration and surface deposition of radioactive materials if the new source term is optimised to this dataset.

\subsection{Database}

A prototype of database of spatiotemporal distribution of radioactive materials in the air and on the ground surface has been developed (Fig. 8). The analysis method to reproduce spatiotemporal distribution of air concentration and surface deposition of radioactive materials for any condition of source term by linear combination of matrix outputs was validated by using sample outputs. While it took several hours to execute usual ATDM simulation, the same outputs were reproduced from matrix outputs by using the analysis function of database within a few minutes. With this result, we confirmed the effectiveness of the analysis method to optimize the new source term and provide results of atmospheric dispersion analysis to other studies for the dose assessment.

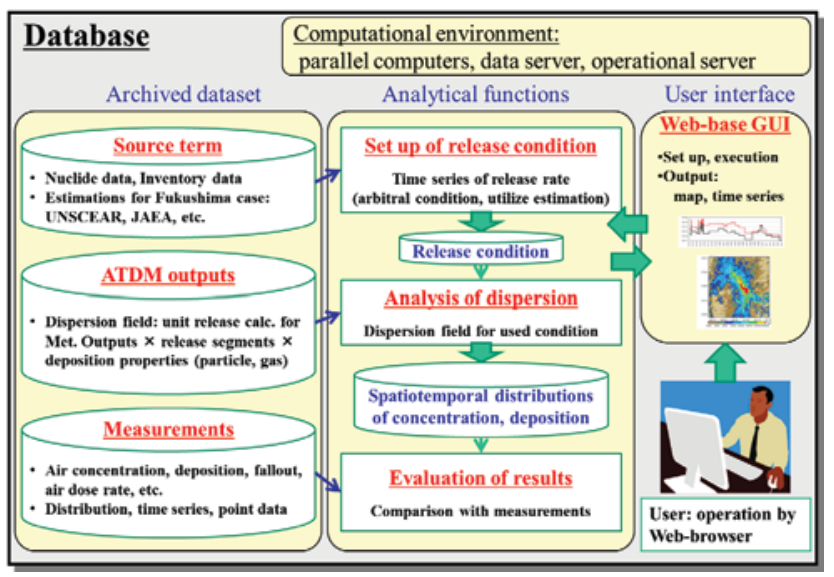

Fig. 8. Schematic design of database of spatiotemporal distribution of radioactive materials.

\subsection{Optimization of the source term}

The optimization of the source term for ATDM simulation with WRF-DA and new GEARN was carried out by comparing hourly air concentration of ${ }^{137} \mathrm{Cs}$ between simulations and measurements [17]. Before the optimization of the source term, statics of the comparison: the percent within a factor of two, five, and ten (FA2, FA5, FA10), correlation coefficient (CC), are summarized in Table 1. In this comparison, statistics were calculated for fractions of samples within specific area and period regarding the plume passage as well as for the total samples. The source term was modified to reduce the discrepancy between simulations and measurements especially for the area and period with low scores (North of FDNPS, Mar. 12-14 and Mar. 1819), where the impact by this discrepancy on the dose estimation is significant. After some modification of the source term, statistics of the comparison became to have higher scores for most cases. Although lower scores for some cases were existed, the reproducibility of atmospheric dispersion processes by the ATDM simulation was improved as a whole by this optimization of the source term. Simulations with the new source term (Katata 2015 source) [9] and optimum source term are compared for the regional ${ }^{137} \mathrm{Cs}$ deposition (Fig. 9), local ${ }^{137}$ Cs deposition (Fig. 10), and local ${ }^{131}$ I deposition (Fig. 11). Although differences between the simulations were small, the deposition patterns by using optimum source term agreed better with measured ones. (a) Katata 2015 source

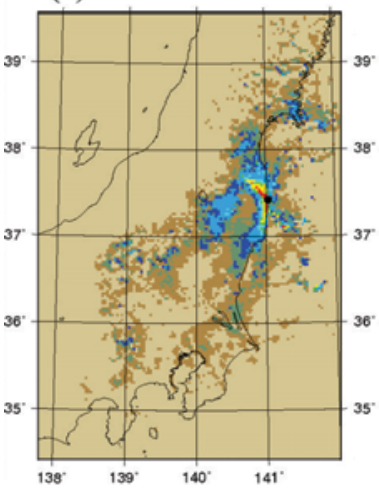

(b) Optimum source

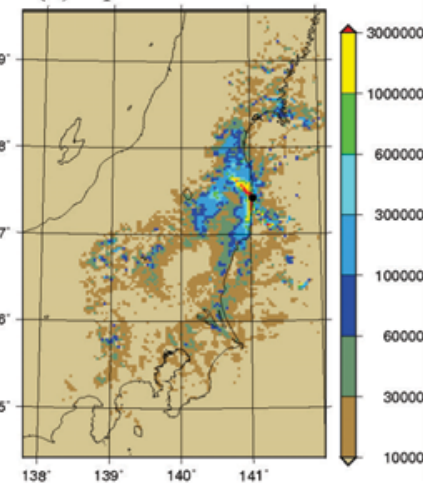

Fig. 9. Deposition patterns of ${ }^{137} \mathrm{Cs}$ of simulations with (a) the Katata 2015 source term, and (b) optimum source term. (a) Katata 2015 source

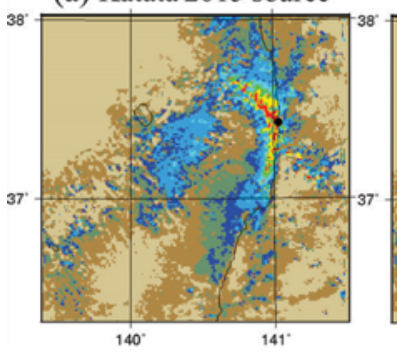

(b) Optimum source

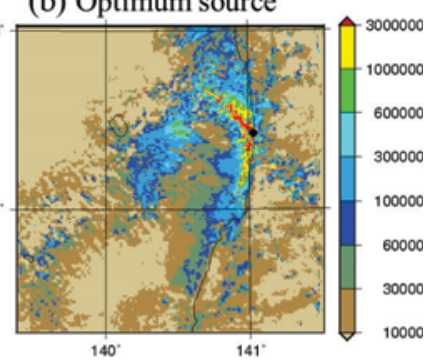

Fig. 10. Local deposition patterns of ${ }^{137} \mathrm{Cs}$ of simulations with (a) the Katata 2015 source term, and (b) optimum source term. 
(a) Katata 2015 source

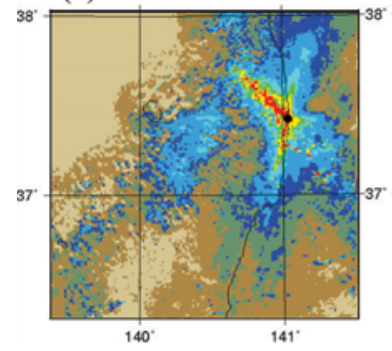

(b) Optimum source

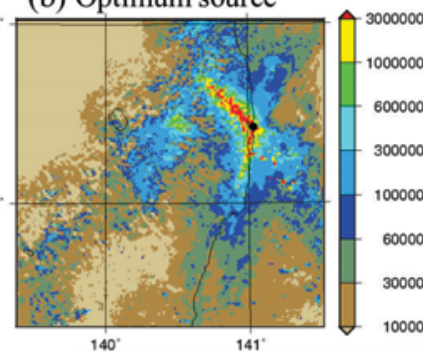

Fig. 11. Local deposition patterns of ${ }^{131} \mathrm{I}$ of simulations with (a) the Katata 2015 source term, and (b) optimum source term.

Table 1. Statics of the comparison: the percent within a factor of two, five, and ten (FA2, FA5, FA10), correlation coefficient (CC), of hourly air concentration of ${ }^{137} \mathrm{Cs}$ between simulations before the optimization and measurements. Statistics were calculated for fractions of samples within specific area and period regarding the plume passage as well as for the total

\begin{tabular}{lcccc}
\hline Area and period & $\begin{array}{c}\text { FA2 } \\
(\%)\end{array}$ & $\begin{array}{c}\text { FA5 } \\
(\%)\end{array}$ & $\begin{array}{c}\text { FA10 } \\
(\%)\end{array}$ & CC \\
\hline $\begin{array}{l}\text { North of FDNPS } \\
\text { Mar. 12-14 }\end{array}$ & 12.0 & 24.0 & 42.0 & -0.20 \\
$\begin{array}{l}\text { Kanto } \\
\text { Mar. 15-16 }\end{array}$ & 16.2 & 37.3 & 49.0 & 0.19 \\
$\begin{array}{l}\text { Fukushima } \\
\text { Mar. 15-16 }\end{array}$ & 13.5 & 35.4 & 44.8 & 0.27 \\
$\begin{array}{l}\text { North of FDNPS } \\
\text { Mar. 18-19 }\end{array}$ & 11.4 & 25.7 & 34.3 & -0.09 \\
$\begin{array}{l}\text { Southern Tohoku } \\
\text { Mar. 20-21 }\end{array}$ & 13.0 & 34.1 & 42.2 & 0.22 \\
$\begin{array}{l}\text { Kanto } \\
\text { Mar. 20-21 }\end{array}$ & 22.7 & 51.4 & 66.3 & 0.69 \\
Total & 17.8 & 41.7 & 54.3 & 0.08 \\
\hline $\begin{array}{l}\text { Southern Tohoku: } \\
\text { Prefectures }\end{array}$ & Fukushima, Miyagi, & and & Yamagata \\
& & & &
\end{tabular}

Table 2. Statics of the comparison: the percent within a factor of two, five, and ten (FA2, FA5, FA10), correlation coefficient (CC), of hourly air concentration of ${ }^{137} \mathrm{Cs}$ between simulations after the optimization and measurements. Statistics were calculated for fractions of samples within specific area and period regarding the plume passage as well as for the total

\begin{tabular}{lcccc}
\hline \multicolumn{5}{c}{ samples. } \\
\hline Area and period & $\begin{array}{c}\text { FA2 } \\
(\%)\end{array}$ & $\begin{array}{c}\text { FA5 } \\
(\%)\end{array}$ & $\begin{array}{c}\text { FA10 } \\
(\%)\end{array}$ & CC \\
\hline $\begin{array}{l}\text { North of FDNPS } \\
\text { Mar. 12-14 }\end{array}$ & 12.0 & 26.0 & 48.0 & -0.16 \\
$\begin{array}{l}\text { Kanto } \\
\text { Mar. 15-16 }\end{array}$ & 16.2 & 37.3 & 49.0 & 0.19 \\
$\begin{array}{l}\text { Fukushima } \\
\text { Mar. 15-16 }\end{array}$ & 15.6 & 34.4 & 46.9 & 0.27 \\
$\begin{array}{l}\text { North of FDNPS } \\
\text { Mar. 18-19 }\end{array}$ & 14.3 & 34.3 & 45.7 & 0.33 \\
$\begin{array}{l}\text { Southern Tohoku } \\
\text { Mar. 20-21 }\end{array}$ & 12.4 & 28.1 & 39.5 & 0.23 \\
$\begin{array}{l}\text { Kanto } \\
\text { Mar. 20-21 }\end{array}$ & 24.1 & 52.0 & 66.9 & 0.71 \\
Total & 18.3 & 41.7 & 54.7 & 0.26 \\
\hline Southern Tohoku: & Fukushima, Miyagi, and & Yamagata \\
Prefectures & & & &
\end{tabular}

\section{Conclusion}

In this study, the source term of radioactive materials discharged into the atmosphere was refined and the ATDM simulation was improved to use a new meteorological model and sophisticated deposition scheme for the accurate assessment of the radiological dose to the public resulting from the FDNPS accident. By using the ATDM simulations, a prototype of database of spatiotemporal distribution of radioactive materials in the air and on the ground surface is also developed. The new ATDM simulation reproduced the ${ }^{137} \mathrm{Cs}$ deposition pattern for the eastern Japan scale better than the former ATDM simulation. Furthermore, the source term was optimized to fit the new ATDM simulation by using new monitoring data that have hourly atmospheric ${ }^{137} \mathrm{Cs}$ concentrations derived by analysing SPM collected at air pollution monitoring station [17]. As the result, the reproducibility of atmospheric dispersion processes by the ATDM simulation was improved, and it can provide better information for the comprehensive dose assessment by the collaborative studies.

The authors express their gratitude to Prof. Hiromi Yamazawa of Nagoya University, Dr. Matthew Hort of UK Met Office, Dr. Werner Rühm of Helmholtz Center Munich, and Dr. André Bouville of National Cancer Institute, NIH, DHHS for their helpful comments and suggestions. This study was conducted in the framework funded and commissioned by Ministry of Environment of Japan.

\section{References}

1. M. Chino, H. Nakayama, H. Nagai, H. Terada, G. Katata, H. Yamazawa, J. Nucl. Sci. Technol., 48, 1129 (2011)

2. G. Katata, H. Nagai, H. Terada, M. Chino, J. Environ. Radioactiv., 111, 2 (2012)

3. G. Katata, M. Ota, H. Terada, M. Chino, H. Nagai, J. Environ. Radioactiv., 109, 103 (2012)

4. H. Terada, G. Katata, M. Chino, and H. Nagai, J. Environ. Radioactiv., 112, 141 (2012)

5. H. Terada and M. Chino, J. Nucl. Sci. Technol., 45, 920 (2008)

6. Y. Morino, T. Ohara, M. Watanabe, S. Hayashi, M. Nishizawa, Environ. Sci. Technol., 47, 2314 (2013)

7. R. Draxler, D. Arnold, M. Chino, S. Galmarini, M. Hort, A. Jones, S. Leadbetter, A. Malo, C. Maurer, G. Rolph, K. Saito, R. Servranckx, T. Shimbori, E. Solazzo, G. Wotawa, J. Environ. Radioactiv., 139, 172 (2015)

8. UNSCEAR (United Nations Scientific Committee on the Effects of Atomic Radiation), UNSCEAR 2013 Report: Sources, Effects and Risks of Ionizing Radiation, Vol. I, United Nations, New York, USA (2014)

9. G. Katata, M. Chino, T. Kobayashi, H. Terada, M. Ota, H. Nagai, M. Kajino, R. Draxler, M. Hort, A. Malo, T. Torii, Y. Sanada, Atmos. Chem. Phys., 15, 1029 (2015)

10. NRA (Nuclear Regulation Authority), Results of the (i) Fifth Airborne Monitoring Survey and (ii) 
Airborne Monitoring Survey Outside $80 \mathrm{~km}$ from the Fukushima Dai-ichi NPP, http://radioactivity.nsr.go.jp/en/contents/6000/5790/ 24/203_0928_14e.pdf (2012, last access: 20 January 2016)

11. T. Torii, T. Sugita, C. E. Okada, M. S. Reed, D. J. Blumenthal, Health Phys., 105, 192 (2013)

12. Fukushima Prefecture, Results of air dose rate measurement on March 2011 (data retrieved from monitoring posts in Fukushima Prefecture), http:/www.atom-moc.pref.fukushima.jp/ monitoring/monitoring201103/201103_mpdata.html, (2012, in Japanese, last access: 12 November 2014)

13. T. Kobayashi, H. Nagai, M. Chino, H. Kawamura, J. Nucl. Sci. Technol., 50, 255 (2013)

14. G. Grell, J. Dudhia, D. Stauffer, A Description of the Fifth-Generation Penn State/NCAR Mesoscale Model (MM5), NCAR Tech, Note NCAR/TN3921STR, National Center for Atmospheric Research, Boulder, Colorado, USA (1994)

15. W. C. Skamarock, J. B. Klemp, J. Dudhia, et al., A description of the Advanced Research WRF Version 3, NCAR Tech. Note NCAR/TN-475STR, National Center for Atmospheric Research, Boulder, Colorado, USA (2008)

16. D. Barker, X-Y Huang, Z. Liu, et al., Bulletin of American Meteorological Society, 93, 831 (2012)

17. Y. Oura, M. Ebihara, H. Tsuruta, T. Nakajima, T. Ohara, M. Ishimoto, H. Sawahata, Y. Katsumura, W. Nittae, J. Nucl. Radiochem. Sci., 15, 15 (2015) 